\title{
EFFECT OF FREQUENCY OF EMISSION ON SEMEN OUTPUT AND AN ESTIMATE OF DAILY SPERM PRODUCTION IN MAN
}

\author{
M. FREUND \\ Department of Physiology and Pharmacology, New York Medical College, \\ Flower and Fifth Avenue Hospitals, New York, U.S.A.
}

(Received 21st March 1963)

\begin{abstract}
Summary. The extra-gonadal sperm reserve (the sperm reserve in the vasa deferentia and the epididymides) was depleted in six donors by an average of 2.4 emissions per day during a 10-day depletion period. Daily sperm output (DSO) was then estimated from the examination of one specimen a day for 24 days. During the Dso period, specimen volume averaged $59 \%$ and sperm concentration per specimen $27 \%$ of that in the control or pre-depletion period. Sperm output per specimen and per week did not return to the levels of the pre-depletion period during a 156-day period (equal to three complete 52-day cycles of spermatogenesis and movement of spermatozoa through the duct system) after the completion of Dso. At a frequency of fewer than five emissions per week, the greatest single influence on sperm numbers in the specimen is the size of the extra-gonadal sperm reserve. Daily sperm output, after the depletion of the extra-gonadal sperm reserve, may be used to estimate daily sperm production (DSP) by the testes. Changes in Dso may be used to measure treatment effects on spermatogenesis. A practical experimental design is proposed for the analysis of factors and treatments affecting DSP in man.
\end{abstract}

\section{INTRODUCTION}

The effects of frequent semen collection have been intensively studied in the dairy bull because of the economic importance of artificial insemination in dairy cattle and because of the value of semen from sires of great genetic merit. Attempts have been made to collect semen from bulls at more frequent intervals (Frederick, 1957; Hupp, Austin, Parish \& Murphree, 1962), to obtain several ejaculates at each collection time (Hafs, Hoyt \& Bratton, 1959; Dukelow, Frederick \& Graham, 1960; Hupp et al., 1962), and to get more spermatozoa per ejaculate by the use of intensive sexual preparation (Collines, Bratton \& Henderson, 1951; Branton, D'Arensbourg \& Johnston, 1952; Hafs \& Knisely, 1960; Hafs, Knisely \& Desjardins, 1962).

Recently, a series of studies has been reported (Hale, Almquist \& Thacker, 1953; Almquist \& Hale, 1956; Almquist, Amann \& O'Dell, 1958; Hale \& 
Almquist, 1960; Almquist \& Amann, 1961; Almquist, Amann \& Hale, 1961; Amann, 1961; Amann \& Almquist, 1961) which makes a major contribution to our understanding of daily sperm production (DSP) in the bull. The review of Hale \& Almquist (1960) and the thesis by Amann (1961) set forth many new data and provocative hypotheses on spermatogenesis, DSP, the extra-gonadal sperm reserve, resorption of spermatozoa, and daily sperm output (DSO) in the bull. DSP is defined as the "total number of spermatozoa produced per day by the two testes" and Dso is defined as the "total number of spermatozoa collected under defined conditions over a period of days, divided by the number of days". These workers suggest that if semen is collected from bulls sufficiently frequently, Dso will begin to approximate DSP (less daily sperm resorption) and that DSo may be used to estimate DSP.

Three practical approaches to the measurement of DSP have been suggested. Ortavant $(1952,1959)$ measured Dso over long periods of time from rams collected by daily electro-ejaculation and proposed a formula for the calculation of DSP from DSO:

$$
\text { DSP }=\text { average DSo for } n \text { days minus } \frac{\left(Q_{1}-Q_{2}\right)}{n}
$$

where $Q_{1}$ is the sperm reserve in the cauda epididymides at the start of the experiment and $Q_{2}$ is the reserve at the end of the experiment. This equation was an attempt to correct for the influence of the sperm reserve in the epididymides during the test period; $Q_{1}$ was estimated and $Q_{2}$ was based on actual epididymal sperm counts made when the rams were killed at the end of the experiment.

VanDemark (1956) and Boyd \& VanDemark (1957) proffered a method for estimating the spermatogenic capacity of bulls based on a series of partial exhaustions (ten consecutive ejaculates within $90 \mathrm{~min}$ ) at 1-, 4- and 7-day intervals. From the differences in sperm number produced by partial exhaustion at the different intervals, they were able to estimate DSP. These methods are impractical for studies with men.

Almquist \& Hale (1956) have suggested that, in the dairy bull, the requirements of Ortavant's formula for calculating DSP may be met by thoroughly depleting the extra-gonadal sperm reserve (collecting ten ejaculates a day for 3 days) and then collecting spermatozoa daily, as rapidly as they are produced, for at least 1 week. Alternatively, they suggest that depletion of the extra-gonadal sperm reserve may be accomplished by removing large numbers of spermatozoa daily for 1 week. When the extra-gonadal sperm reserve is thoroughly depleted before daily collection begins, $Q_{I}$ in Ortavant's formula becomes approximately equal to $Q_{2}$, and Dso may be used to estimate DSP. This method does not involve killing the animal and avoids the build-up of sperm reserves which is a problem when bulls are partially exhausted at 7-day intervals. This method seems practical for use in studies with men if the preliminary depletion period is extended from 3 to 10 days and the number of specimens collected per day is lowered from ten to two or three.

A previous study in this laboratory (Freund, 1962) has demonstrated marked differences in the effects of increasing the frequency of emission on semen production in man as compared to the bull. Hafs et al. (1959) found that bulls which 
ejaculated once a day produced 1.9 times as many spermatozoa per week as did other bulls from which spermatozoa were collected once a week. Dukelow, Frederick \& Graham (1960) found, in definitive long-term studies with monozygotic twin and triplet bulls, that when ejaculation frequency was increased from two to seven times per week, $2 \cdot 1$ times as many spermatozoa per week were ejaculated at the higher frequency as at the lower frequency. However, Freund (1962) demonstrated that when emission frequency in man was increased from 3.5 to 8.6 times per week, the total number of spermatozoa produced per week declined from $742.70 \times 10^{6}$ to $515.83 \times 10^{6}(-31 \%)$, even though the volume of semen produced per week increased from 10.43 to $17.20 \mathrm{ml}(+39 \%)$. The decrease in total number of spermatozoa produced per week by man, at the higher frequency, occurred in spite of the increase in semen volume per week because sperm concentration per specimen declined so much more markedly $\left(212.20 \times 10^{6}\right.$ to $\left.59.90 \times 10^{6}\right)$ than did specimen volume $(2.98 \times 2.00 \mathrm{ml})$, with the result that sperm concentration per millilitre of semen fell precipitously $\left(73.46 \times 10^{6}\right.$ to $\left.32.51 \times 10^{6}\right)$. In Dukelow's study with the bull, sperm concentration per millilitre did not decline at the higher frequency because the number of spermatozoa and the volume of semen per ejaculate declined at the same rate. In Hafs's study with the bull, sperm concentration did markedly decline but was more than compensated for by a very large increase in semen volume ( 9.5 to $43.3 \mathrm{ml}$ per week). It was concluded that, unlike the bull, man cannot replenish or even maintain his extra-gonadal sperm reserve at a frequency of 8.6 emissions per week and that DsP could be estimated from Dso in man provided the measurement of Dso followed the exhaustion of the extra-gonadal sperm reserve.

There have been reports on the effect of increase in emission frequency in man. MacLeod \& Heim (1945) examined a specimen each day for 3 days from eighteen donors, after 7 to 10 days of continence, and reported a decline in sperm concentration and specimen volume. Lampe \& Masters (1956) received five specimens, at 12-hr intervals, from each of twenty-one donors after 3 to 5 days of continence. They found that sperm concentration and specimen volume declined through $24 \mathrm{hr}$ but then tended to recover by $48 \mathrm{hr}$. Murphy (1962) studied a single donor who produced repeated specimens at 1 -hr intervals for $4 \mathrm{hr}$, after 5 days of continence, and noted that concentration and volume declined markedly. In no case was there any consideration of the effect of the extra-gonadal sperm reserve on the subsequent emissions. It is evident that periods of continence prior to the experimental period tend to increase the size of the extra-gonadal sperm reserve and so confound the results.

The general plan of this study was to examine a series of successive semen specimens from each of a group of unselected donors, during a control or preexperimental period, during a 10-day period for depletion of the extra-gonadal sperm reserve, during a period of Dso, and during subsequent recovery and control periods. These data should provide the basis for a definitive evaluation of the importance of frequency of emission on sperm output and should permit an estimate of DSP in man. 


\section{METHODS}

The specimens used in this investigation were received from six medical students, 21 to 31 years old, who had agreed to follow the experimental collection schedule and to report all outside emissions during the course of the study. Four of the donors were married (Nos. 1, 2, 3 and 4). No selection of donors or of specimens was made at any time during the course of this study.

The specimens were collected at home by the donors in clean dry sputum bottles and the time of collection and the dates of the last two or three emissions were recorded on the bottle label. When one specimen per day was required, it was collected in the morning and brought directly into the laboratory. When more than one specimen per day was required or on Saturdays, Sundays and holidays, the specimens were collected at home, kept in the refrigerator, and brought into the laboratory on the morning of the next working day. Motility and forward progression were not rated in these older specimens.

The methods used to measure semen characteristics followed the outline set up by the American Society for the Study of Sterility in the handbook, Evaluation of the barren marriage, and have previously been described in some detail (Freund, 1962).

The collection schedule provided for five experimental periods:

(1) Control period 1 (60 to 67 days). Two specimens per week (Monday and Thursday) were examined and outside emissions were recorded.

(2) Depletion period (10 days). The donors collected as many specimens as possible each day and averaged 2.4 emissions per day during this phase of the study (Table 1 ). An average of 2.32 specimens per donor per day was examined and outside emissions were recorded.

(3) Daily sperm output period (24 days). One specimen per day was examined and outside emissions were recorded.

(4) Recovery period (104 days). Two specimens per week (Monday and Thursday) were examined and outside emissions were recorded over a period approximating to two complete cycles of spermatogenesis and movement of the spermatozoa through the duct system.

(5) Control period 2 (52 days). Two specimens per week (Monday and Thursday) were examined and outside emissions were recorded over a period approximating to one complete cycle of spermatogenesis and sperm migration.

In a study of this type, which extended over a period of 8 months, the effect of emissions outside of the study must be considered. The proportion of total emissions which were examined, i.e. the ratio of the number of specimens examined to the total number of emissions, varied during the different periods of the study: $58 \%$ of the total number of emissions were examined during control period 1,96\% during the depletion period, $74 \%$ during the Dso period, $61 \%$ during the recovery period, and $53 \%$ during control period 2 (Table 1). It was previously shown (Freund, 1962) with this same group of donors that the masturbated semen specimen is representative of the ejaculate produced at intercourse. Therefore, the measurements of semen characteristics made on the specimens brought into the laboratory, together with the total 
number of emissions reported, were used to calculate the total sperm output during each period.

\section{RESULTS AND INTERPRETATION}

The requirements set by Almquist \& Hale (1956), Amann \& Almquist (1961), and Hupp et al. (1962) for depletion of the extra-gonadal sperm reserve and for the measurement of Dso in the bull have been successfully met in a group of six men. During the 10-day period provided for depletion of the sperm reserve, these men produced an average of 24.2 emissions (Table 1 ). This exceeds the requirement that large numbers of spermatozoa must be removed daily for 1 week to deplete the extra-gonadal sperm reserve. The donors then collected one specimen per day for 24 days (Table 1) for the measurement of Dso, which meets the further requirement that there be short and uniform intervals between collections during an experimental period with a duration of at least 2 weeks. During the Dso-measurement period, when each donor brought in one specimen a day for examination, the donors reported a mean of 8.2 outside emissions for an average of 32.2 ejaculations during the 24-day period (1.34 emissions per day for 24 days).

The increase in emissions from 3.2 per week during control period 1 to 16.9 per week during the depletion period resulted in a decline of $64 \%$ in average sperm concentration per millilitre, $47 \%$ in average specimen volume, and $84 \%$ in average sperm concentration per specimen (Table 2). These marked decreases in sperm numbers and specimen volumes were uniform and typical of all the donors. A careful examination of the day-to-day records during the depletion period indicates that there was no steady and uniform decrease in sperm numbers and specimen volumes from Day I to Day 10. On the contrary, sperm numbers and specimen volumes reached their low points for the 10-day depletion period during the 2 nd day and remained low thereafter. These data confirm the previous report (Freund, 1962) that the sperm reserve in man is small compared to the bull, and that this reserve may readily be depleted by an increase in emission frequency.

There was no apparent or uniform effect of the large increase in emission frequency during the depletion period, on the motility or forward progression of the spermatozoa (Table 3). The total number of spermatozoa and the number of motile spermatozoa produced per week did not increase when emission frequency rose from 3.2 per week during control period 1 to 16.9 per week during the depletion period (Table 4). In spite of the very great increase $(185 \%)$ in the volume of semen produced per week at the higher frequency, there was no consistent increase in sperm number per week; three of the donors showing an increase and three a decrease (Table 4). These data support the earlier finding (Freund, 1962) that when emission frequency was increased from 3.5 per week to 8.6 per week, there was actually a decrease in the total number of spermatozoa and in the number of motile spermatozoa produced per week, even though the volume of semen per week increased markedly.

There was no change in the outside emission frequency during the Dso period as compared to control period 1 (Table 1), i.e. the outside emission 


\begin{tabular}{|c|c|c|c|}
\hline \multirow{3}{*}{ 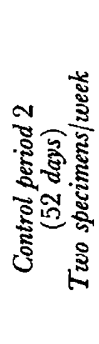 } & 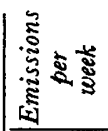 & $\begin{array}{l}\stackrel{+}{+}+\dot{H} \tilde{\sim} \\
\dot{\sigma} \dot{\sim} \dot{\sim}\end{array}$ & $\dot{m}$ \\
\hline & ڤ్ & 䒘우욣 & $\stackrel{\sim}{\dot{d}}$ \\
\hline & रे & 으묘む요 & $\stackrel{P}{ \pm}$ \\
\hline \multirow{3}{*}{ 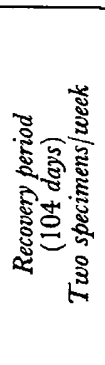 } & 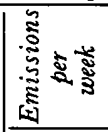 & 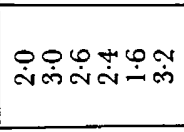 & $\ddot{\sim}$ \\
\hline & 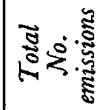 & 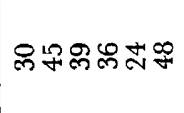 & $\stackrel{0}{\stackrel{0}{n}}$ \\
\hline & 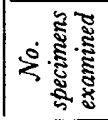 & ปัผลัฮละ & $\tilde{\dot{\sim}}$ \\
\hline \multirow{3}{*}{ 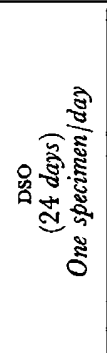 } & 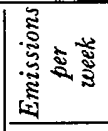 & 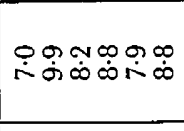 & $\stackrel{+}{\infty}$ \\
\hline & 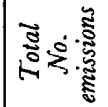 & 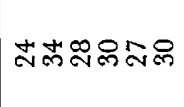 & $\stackrel{\sim}{\ddot{~}}$ \\
\hline & ن. & 志志志志 & $\stackrel{+}{\dot{H}}$ \\
\hline \multirow{3}{*}{ 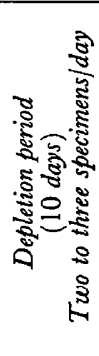 } & 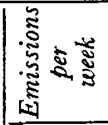 & 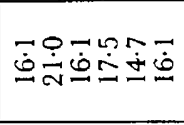 & $\stackrel{9}{\dot{\theta}}$ \\
\hline & 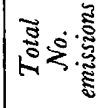 & 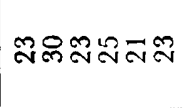 & $\stackrel{\text { I }}{\mathrm{H}}$ \\
\hline & 蛋 & స్లి సొస్లి & ஸें \\
\hline \multirow{3}{*}{ 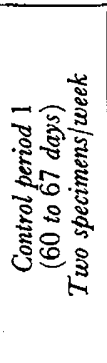 } & 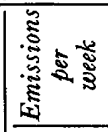 & 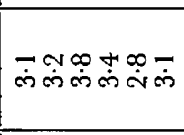 & $\ddot{m}$ \\
\hline & $\bar{\Xi}$ & 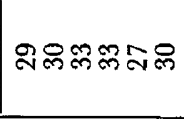 & 官 \\
\hline & 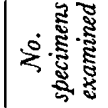 & 으요 & 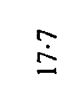 \\
\hline \multicolumn{2}{|c|}{ 离定 } & -NMtion & 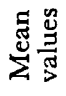 \\
\hline
\end{tabular}

\begin{tabular}{|c|c|c|c|}
\hline $\begin{array}{l}4 \\
\frac{1}{4} \\
\vdots \\
0\end{array}$ & & हैं & 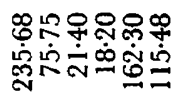 \\
\hline 委 & 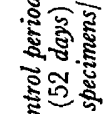 & 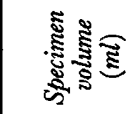 & 乌ి \\
\hline $\begin{array}{l}\text { wo } \\
z \\
0\end{array}$ & త & हैं & 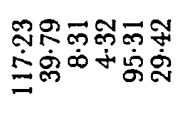 \\
\hline 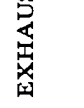 & & हैं & 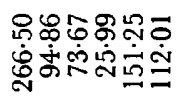 \\
\hline$\vec{F}$ & 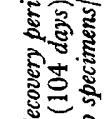 & हैँ & 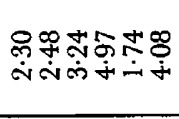 \\
\hline 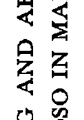 & $\approx$ & 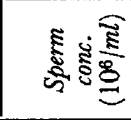 & 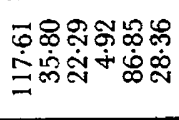 \\
\hline 皆 & & है: & 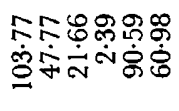 \\
\hline 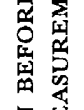 & 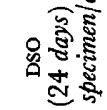 & 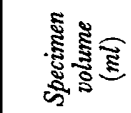 & 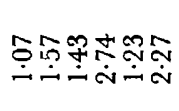 \\
\hline 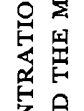 & & & 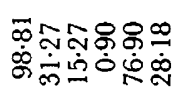 \\
\hline $\begin{array}{l}0 \\
2 \\
0 \\
8 \\
0\end{array}$ & & हैं & 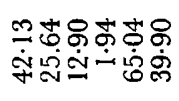 \\
\hline 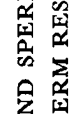 & 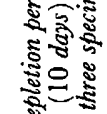 & 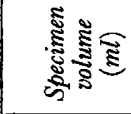 & 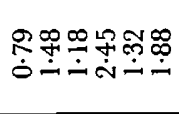 \\
\hline 这 & N & 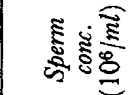 & 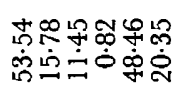 \\
\hline 丞 & 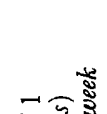 & हैं & 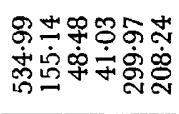 \\
\hline 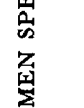 & 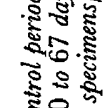 & 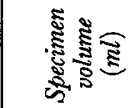 & 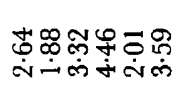 \\
\hline 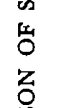 & & 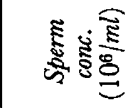 & 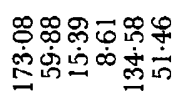 \\
\hline 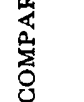 & & & 0 \\
\hline
\end{tabular}




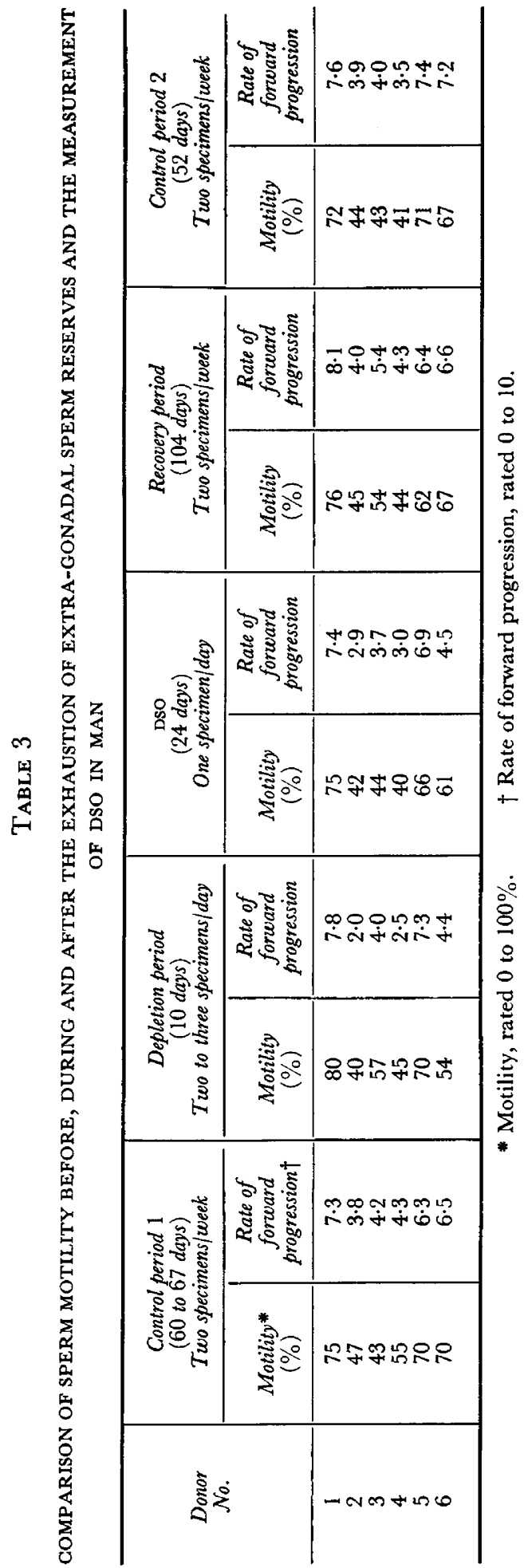

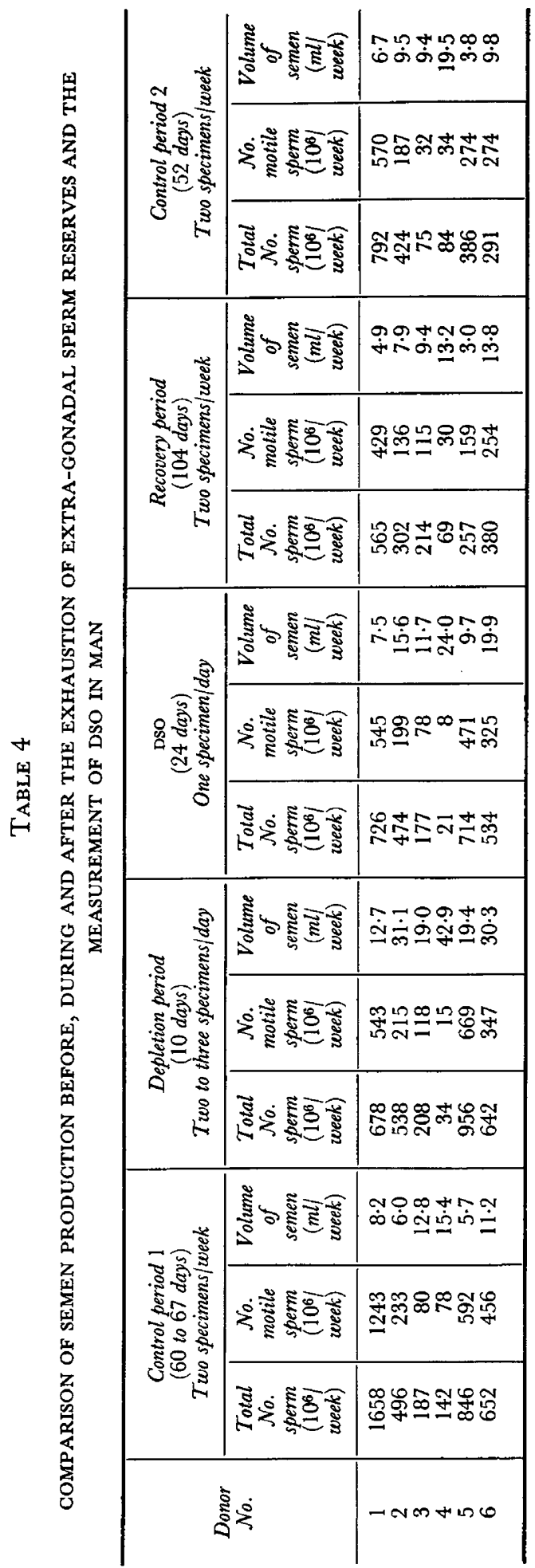


frequency was $1.2(3.2-2 \cdot 0)$ per week during the control period, and 1.4 $(8 \cdot 4-7 \cdot 0)$ per week during the Dso period, so that this could not have influenced the comparison. Sperm number and specimen volume during Dso averaged about one-half of the corresponding values during the control period (Table 2). During the Dso period, sperm concentration per millilitre averaged $55 \%$, specimen volume $59 \%$, and sperm concentration per specimen $27 \%$ of
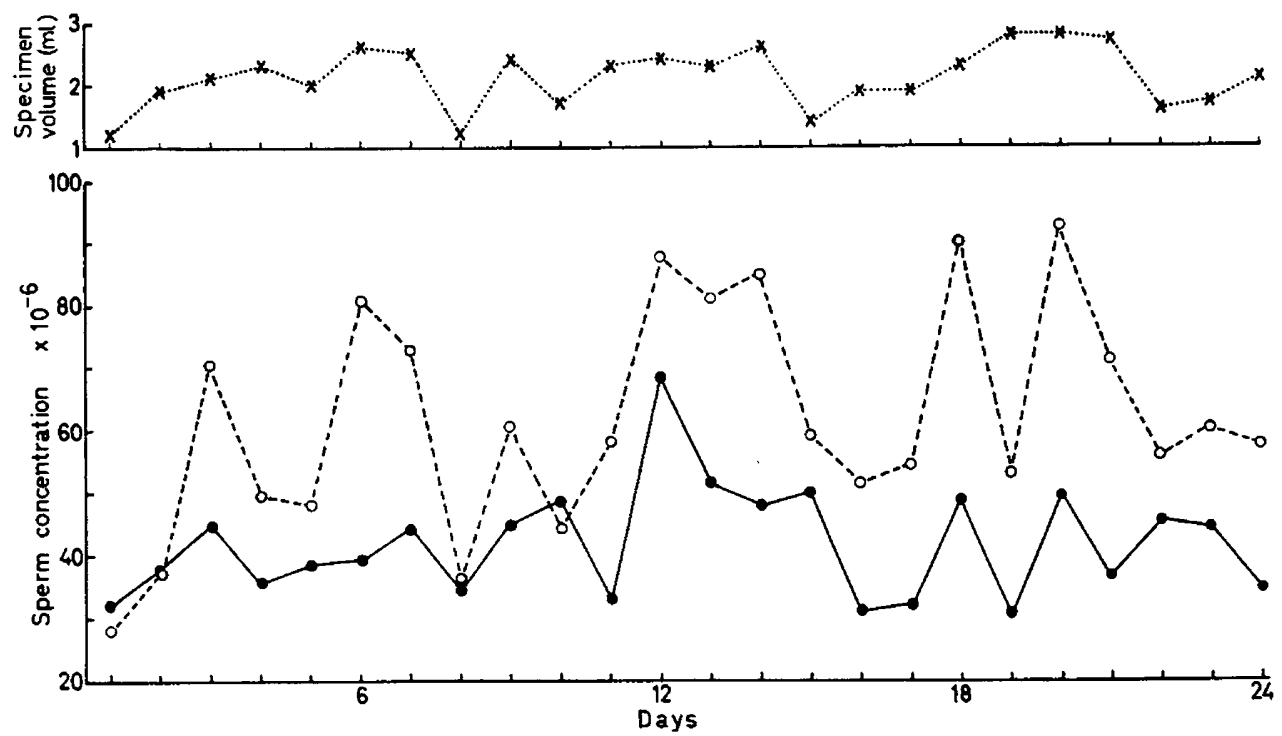

TeXT-FIG. 1. Mean semen production during the measurement of Dso. $\bullet$, Sperm concentration per $\mathrm{ml} ; 0$, Sperm concentration per specimen.

that in control period 1. However, Donors 3 and 4 (Table 2) varied widely from this average. No marked difference in sperm motility or forward progression was apparent during the Dso period as compared to the control period (Table 3). The total number of spermatozoa per week and the number of motile spermatozoa per week produced during the Dso period was, in the case of each of the six donors, less than the corresponding value for the control period (Table 4). This was true although, on the average, there was a considerable increase in the volume of semen produced per week during the Dso period (Table 4). Therefore, this marked drop in total spermatozoa and in motile spermatozoa per week was due primarily to the very severe decline in sperm concentration per specimen, i.e. in the total number of spermatozoa in each ejaculate, at the higher frequency of emission.

There was a very large day-to-day variation within donors in the values for sperm concentration per millilitre and per specimen during the measurement of Dso, when daily specimens were examined after the depletion of the sperm reserve. Since these data are extensive, the mean day-to-day variations are presented graphically (Text-fig. 1). A further examination of the data by donors for sperm concentration per specimen, i.e. the total number of spermatozoa in the ejaculate, during the 24-day period of measurement of Dso, indicates (Text-fig. 2) that this day-to-day variability is characteristic of each of the 
donors. For the sake of clarity, only the mean values of the study for sperm concentration per specimen, the values for the donor with the highest sperm concentration (Donor 1, Table 2) and the values for the two donors with the lowest sperm concentrations (Donors 3 and 4, Table 2) have been included in the graph. The other three donors in this study were intermediate in terms of sperm concentration per specimen and displayed the same order of day-to-day

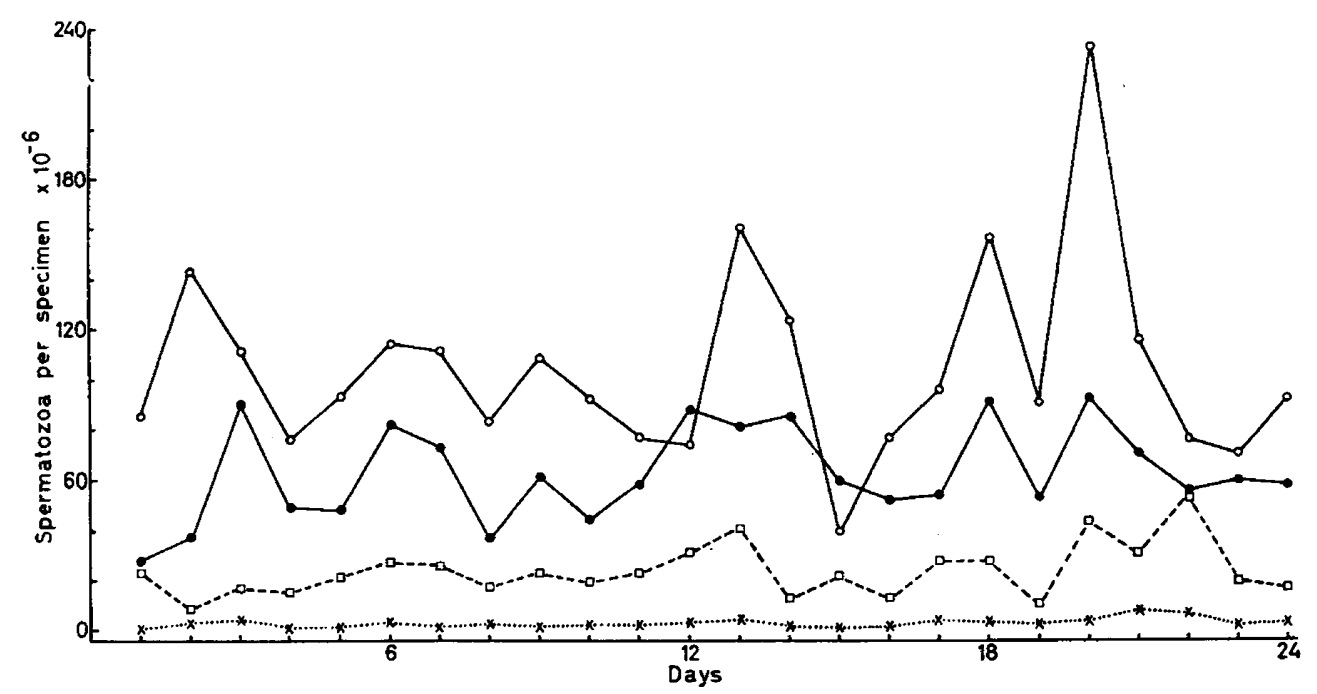

TEXT-FIG. 2. Sperm concentration per specimen, by donors, during measurement of Dso. 0 , Donor 1; $\square$, Donor 3; $\times$, Donor 4; $\mathbf{e}$, Mean Dso.

variability. The large day-to-day variation in sperm output is apparent and the possible physiological mechanisms involved will be considered in the Discussion.

The most striking fact apparent during the 104-day recovery period, after the completion of Dso, and during the subsequent 52-day control period 2, was that sperm concentration per millilitre and per specimen (Table 2) and total sperm output per week (Table 4) did not return to the levels of control period 1, the period prior to the depletion and Dso periods. A 104-day recovery period was chosen since it was assumed that this period of time best approximated two complete 52-day (49- to 55-day) cycles of spermatogenesis and movement of spermatozoa through the duct system. A subsequent 52-day control period 2 was used for comparison with the pre-treatment control period 1. The failure of sperm output values to return to their pre-depletion levels indicates that either (1) the complete reconstitution of the extra-gonadal sperm reserve in man after rigorous depletion takes more than three 52-day cycles or (2) the depletion and daily specimen regimen adversely affected the subsequent rate of spermatogenesis. This is further evidence in support of the statement that an accurate estimate of sperm production cannot be made in the presence of the extra-gonadal sperm reserve since the size of the reserve plays such an important role in the number of spermatozoa which appear in the specimen. 


\section{DISGUSSION}

The nature of the data in this study and in a preceding one (Freund, 1962), calls for a re-examination of some of the older concepts and methods used in studies of semen production in man. These data indicate that the examination of a single specimen from a donor cannot result in data which will yield an estimate of a man's semen production accurate enough for use in a research study. Such a single determination may suffice for the purpose of clinical diagnosis. However, the variability in human semen production is so great, the influence of emission frequency is so large, and the confidence limits for a single determination are so broad, that the data from the examination of a single specimen cannot yield a reliable research estimate of a donor's semen production. It is evident that without repeated specimens, under controlled conditions, no estimate of the variation among specimens within donor can be made. Without such an estimate of within-donor variation, no conclusive test of the significance of the differences among donors, among fertile and infertile groups, or among treated and control groups can be made.

These data show conclusively that sperm concentration per specimen on Dso was only about one-quarter of that during control period 1 , when the emission frequency was 3.2 times per week. In other words, when a semen specimen is brought in for examination by a man whose regular frequency of emission is less that five times per week, the greatest single influence on sperm number in the specimen is the size of the extra-gonadal sperm reserve. This type of specimen reflects little or nothing of the actual DSP by the testes. Under these circumstances, one must view many of the reports on the effects of drugs and hormones in increasing sperm production with reserve. The basic question in this type of study must be whether the treatment affects spermatogenesis, i.e. the actual output of mature spermatozoa from the testes to the epididymides. The standard technique has been to examine one or more specimens while the donor continues his usual frequency of outside emission and to consider this as the pretreatment control. Some investigators have even requested a period of continence before a specimen is produced (MacLeod \& Heim, 1945; MacLeod \& Hotchkiss, 1946; MacLeod \& Gold, 1951; Lampe \& Masters, 1956; Murphy, 1962); a practice which further confounds the data since it causes an increase in the size of the extra-gonadal sperm reserve. Then the donor is treated for a variable period of time with the drug or hormone being tested. After another variable period of time, after treatment, he is requested to bring in one or more specimens and the data collected from the examination of these specimens are studied for treatment effects. This type of study cannot determine the effect of the treatment on spermatogenesis since the greatest part of the variation in the total number of spermatozoa seen in each of the specimens reflects variation in the extra-gonadal reserve, rather than in spermatogenesis.

The number of spermatozoa available for ejaculation in the extra-gonadal reserve is the result of the interaction of (1) DSP by the testes, (2) resorption of spermatozoa in the epididymides, and (3) rate of removal of spermatozoa from the extra-gonadal reserve by ejaculation. At low frequencies of emission, the rate of removal would be the chief variable affecting the sperm reserve and the 
reserve would be, in turn, the chief variable affecting sperm number per specimen.

At a high and constant frequency of emission, e.g. daily semen specimens after exhaustion of the extra-gonadal sperm reserve, the rate of resorption of spermatozoa in the epididymides would be the chief factor affecting sperm number per specimen. If the rate of sperm resorption in the epididymides is constant, Dso would bear a constant relationship to DsP and changes in Dso could be used as a measure of treatment effects.

An experiment to determine the effect of a treatment on spermatogenesis in man, i.e. on the actual output of mature spermatozoa by the testes to the epididymides, would have to be based on the measurement of Dso. The most straightforward experimental design would require the depletion of the extragonadal sperm reserve by a period of frequent ejaculation (two to three specimens per day for 10 days) followed by a long period for the measurement of Dso (one specimen per day). This period of oso would constitute the pre-treatment control and would serve as an estimate of DSP. Ideally, this Dso-control period should extend over at least one full cycle of spermatogenesis and migration of spermatozoa through the duct system ( 49 to 55 days). After this control period has been completed, the treatment would be applied for one or more cycles $(52,104$ or 156 days). It is unreasonable to assume that a short course of treatment, e.g. oral administration of thyroid hormone for only 10 to 20 days, could have anything more than the most transient effect on spermatogenesis. It is most unlikely that such a transient effect could be observed by the use of the present techniques of semen examination. The cyclic nature of spermatogenesis is apparent and the effects (if any) of such a treatment would most probably be on one or more of the discrete steps in the cycle. This means that such a treatment would have to be applied for at least one full cycle ( 52 days) if its effects are to be apparent during the whole of the succeeding cycle. The effects of the applied treatment should begin to appear $52 \pm 3$ days after treatment has begun, should continue thereafter as long as the treatment (or treatment effect, as in the case of irradiation) continues, and should begin to disappear $52 \pm 3$ days after the treatment or treatment effect ends. Daily specimens examined throughout this time would show onset, duration, extent, and termination of treatment effects on DSP by the testes. The data collected during the control or pre-treatment cycle would be used to establish an error term based on the large variability which has been reported in this study among specimens from the same donor on Dso. The difficulties involved in carrying out such a critical study are apparent and it would seem most impractical to expect the donors to collect daily specimens for such long periods of time.

Therefore, an alternative experimental design is suggested for this type of study which would not require such extended periods of Dso and which would yield useful estimates of the data which could be derived from the more critical approach. The data in this study have shown that the collection of three specimens per day for 3 consecutive days would result in an adequate depletion of the extra-gonadal sperm reserve. These data also indicate that one specimen each day for 5 days would provide a useful estimate of Dso. There is no indication from these data that the problem of change in the rate of sperm resorption in the 
epididymides, which Amann \& Almquist (1961, 1962) reported for the bull, exists in man. Therefore, it is suggested that a 3-day period of intensive depletion of the sperm reserve followed by a 5-day Dso period would serve as a control or pre-experimental estimate of DSP by the testes. The treatment would then be applied (e.g. for three cycles or 156 days) and the treatment effects would be determined by measurement of Dso at 52, 104, 156 and 208 days after the beginning of the treatment. At each time, 5 days of Dso would be preceded by depletion of the extra-gonadal sperm reserve (three specimens per day for 3 days). It is believed that this is a practical approach to the measurement of the effect of a treatment on spermatogenesis in man. A study is now in progress to test the validity of this experimental design.

The wide day-to-day variability in sperm number in specimens from the same man, when the donors were on Dso after a 10-day period of depletion of extra-gonadal sperm reserves, requires analysis. A large part of the variability found in a previous study (Freund, 1962) occurred because the sperm reserve had not been depleted prior to the collection of daily specimens. An examination of the data in this study (Text-fig. 1), where the sperm reserve was depleted, demonstrates considerable day-to-day variation in Dso.

One may consider that variation in Dso is (1) the result of some as yet unidentified cycle (diurnal or periodic), (2) due to variability in the extent and/or completeness of emptying of the contents of the ampullae, vasa deferentia, and cauda epididymides, (3) accurately reflects a similar variation in DSP, i.e. in spermatogenesis itself, or (4) the product of variation in sperm resorption in the epididymides.

Doggett has claimed that there exist regular periods in sperm output in both rabbit (1956) and man (1962) with peaks of sperm concentration appearing regularly at 3- to 4-day intervals and that the day-to-day variation in sperm output is due to this periodicity. She has published graphs which purport to demonstrate these cycles. However, in her studies, extra-gonadal sperm reserves were not depleted and so her data cannot be considered to be a reflection of DSP by the testes. Furthermore, a serious systematic error has been introduced into the rabbit data by improperly plotting all semen characteristics as zero when the animal failed to produce a specimen. This is exemplified in Fig. 1 of her report (Doggett, 1956) where 7 out of a total of 44 points are zeros which were arbitrarily inserted into the data when there was a failure to collect a specimen on each of those 7 days. These inserted zeros are not a reflection of 'no sperm output' but rather of failure of the method of semen collection. Under these circumstances, visual inspection of the graphs in this work offers no clue to the existence of any periodicity. The statistical methods (chi-square test) applied to her data are of little value since Doggett reports day-to-day variation of the order to 5 to 50 times, e.g. $\cong 5 \times 10^{6}$ total spermatozoa on 1st March and $\cong 250 \times 10^{6}$ total spermatozoa on 2nd March for the rabbit in Fig. 1 of her paper (Doggett, 1956). She has advanced no suggestion as to what the physiological basis for such a 3- to 4-day periodicity might be. There would seem to be no evidence to support the idea that the variation in Dso is due to periodicity. 
It has been shown that, in the dairy bull, the degree of sexual excitation affects both semen specimen volume and sperm number. If the bull is required to make several 'false mounts' before ejaculation, he will produce more spermatozoa and more seminal plasma per ejaculate. The physiological mechanism underlying this observation has not been explained although the observation has been confirmed (Collines et al., 1951; Branton et al., 1952; Hafs \& Knisely, 1960). It may be suggested that the increase in sperm number and seminal plasma volume is due to a more complete emptying of the extra-gonadal sperm reserve, i.e. of the ampullae, vasa deferentia and cauda epididymides, and of the accessory glands, and that this is probably mediated through an increase in autonomic nervous activity. Copulation, i.e. the complete sequence of erection, extrusion, intromission, thrust and ejaculation, takes only a very short time (13 to $40 \mathrm{sec}$ ) in the bull (Frederick, 1957). This is due to the presence of the fibro-elastic type of penis which is firm in the non-erect state and which rapidly becomes more rigid upon erection with little change in length or diameter. The time from intromission to ejaculation is only a few seconds in the bull since the copulatory thrust reflex is elicited primarily by the warmth of the vagina and only secondarily by friction between the vagina and penis. However, the integrated process of erection, coition and ejaculation in man is quite different from the process in the bull. Man has the vascular type of penis which is flaccid in the non-erect state and which requires frictional and/or psychic stimulation for erection. Erection is the result of the relatively slow process of filling of the intratrabecular spaces of the corpora cavernosa with blood, and results in a marked increase in penile length and diameter. Although there are no published data available, erection in man must take very much longer that it does in the bull. The time from intromission to ejaculation must be relatively longer in man, as in other animals with the vascular type of penis, since it is the psychic stimuli, the pressure of the vagina, and the friction of coition, rather than the warmth of the vagina, that elicits the ejaculatory reflex. Thus, a relatively large degree of physical and psychic stimulation, extending over a considerable period of time, would seem to be normal components of copulation in man in contrast to the bull. In an earlier study (Freund, 1962), it was shown that there was no difference among masturbated specimens and specimens collected in condoms at intercourse by the same donors. Thèse data suggest that any extra sexual excitement of intercourse over masturbation does not result in the ejaculation of more spermatozoa or seminal plasma or that the sexual excitation at masturbation is sufficient to result in complete ejaculation. In either case, there are no grounds for assuming that differences in degree of sexual excitation affect sperm number or specimen volume in man. Evidently, since considerable physical stimulation is required either for copulation or for masturbation in man, small variations in psychic excitation and their effect on the semen specimen would be most difficult to measure. There are no experimental data to provide the basis for an assumption that the variability in Dso in man could be ascribed to variation in the degree of sexual excitation and to the resulting differences in completeness of ejaculation.

It must also be pointed out that the work on the effect of sexual excitation in the bull was done at very low frequencies of collection, (one ejaculation per 
week), and that sperm reserves were, therefore, a major factor in the results. It is quite possible that such studies, repeated on bulls which have had their extra-gonadal sperm reserves depleted and which are on a daily collection schedule, might not show any result of sexual excitation on sperm number and ejaculate volume.

The possibility exists that the variability in Dso in man is due to a similar variation in DSP by the testes. This hypothesis implies that the postulated daily variations in spermatogenesis are reflected some 16 to 18 days later when the spermatozoa have completed their migration through the epididymides and are ejaculated. No evidence for such day-to-day variability in spermatogenesis is available.

Little is known about sperm resorption in the epididymis of the bull (Amann \& Almquist, 1961, 1962) and nothing is known about such resorption in man. Therefore, the influence of sperm resorption in the epididymis on the day-to-day variation in sperm output in man must remain a matter for speculation.

It is evident that the day-to-day variation in Dso within donors is large and that it must be taken into account in the design of studies to measure the effects of a treatment on DSP. The random day-to-day fluctuations in sperm output are so great that the error of a single sampling must be very large and, therefore, the confidence limits must be exceedingly wide. Under these circumstances, the examination of a single semen specimen, even after the depletion of the extra-gonadal sperm reserve, can yield only a very general estimate of the mean sperm production by the donor. Certainly, the examination of a single specimen will not result in data which can be used to predict accurately the level of semen production of the donor. Repeated daily specimens, after the depletion of the extra-gonadal sperm reserve, are required in order to arrive at a reasonable estimate of sperm production by the donor.

It is proposed, as a result of this study and of a preceding one (Freund, 1962), that sperm concentration per specimen (the total number of spermatozoa in the ejaculate), is a more reliable and useful measure of sperm production in man than is sperm concentration per millilitre. Sperm concentration per specimen (total spermatozoa) is independent of specimen volume while sperm concentration per millilitre is related to, and dependent on, specimen volume in a complex manner.

In previous studies with human semen (Hotchkiss, Brunner \& Grenley, 1938; Harvey \& Jackson, 1945; MacLeod \& Heim, 1945; MacLeod \& Hotchkiss, 1946; MacLeod \& Gold, 1951), it was implicit that the seminal plasma, an independent variable, was simply a diluent which mixed with the total number of spermatozoa, a second independent variable, at ejaculation. Therefore, it followed that sperm concentration per millilitre was a direct reflection of the degree of dilution of the spermatozoa by the seminal plasma. Hence, it was assumed (MacLeod \& Gold, 1951) that sperm concentration per millilitre was as repeatable and useful a measure of sperm production as was sperm concentration per specimen. Consideration of these terms is confused by the fact that it is the sperm concentration per millilitre which is actually determined by haemocytometer count and that the sperm concentration per specimen (total spermatozoa) is calculated by multiplying the sperm concentration per milli- 
litre by the specimen volume in millilitres. Nevertheless, in terms of the physiology involved, it is the sperm concentration per specimen divided by the specimen volume per millilitre which yields the sperm concentration per millilitre. The simple concept that sperm concentration per specimen and seminal plasma volume are two independent variables that may be combined to yield a single useful measure of sperm production, sperm concentration per millilitre, is not tenable when the data are examined.

These data (Table 2) support the observation (MacLeod \& Gold, 1951) that specimens from oligospermic men tend to have low sperm concentration per millilitre and high specimen volume, i.e. that there is a negative relationship between specimen volume and sperm concentration per millilitre on an amongdonors basis. The physiological basis for the association of low sperm count and high specimen volume in specimens from the oligospermic donor remains unexplained. Furthermore, it has recently been demonstrated (Freund, 1962) that there is a significant positive correlation between sperm concentration per millilitre and specimen volume on a specimens-within-donor basis but not on an among-donors basis, i.e. that the better specimens from the same donor tend to be higher in both sperm concentration per millilitre and in specimen volume. Evidently, the among-donors effect and the specimens-within-donor effect on sperm concentration per millilitre oppose each other, e.g. there is an association among donors between low sperm count and high specimen volume, while high count and high volume are associated among specimens within donors.

The problem of assessing the value of the sperm concentration per millilitre is further complicated by the fact that at very high frequencies of emission, as in this study, the seminal plasma is replaced at a much faster rate than are the spermatozoa available for ejaculation in the epididymides and vasa deferentia. The result is that the sperm concentration per specimen falls much more rapidly and markedly than does the specimen volume (Table 2 and Freund, 1962, Table 5). Thus the fall in sperm concentration per millilitre does not truly reflect the fall in the total number of spermatozoa ejaculated per specimen and per week at the high frequencies of emission.

Furthermore, it must be kept in mind that the period of replacement of seminal plasma by the accessory glands after ejaculation is somewhat more than $24 \mathrm{hr}$ (Freund, 1962) while the time required for a full cycle of spermatogenesis and sperm migration through the duct system is probably about 49 to 55 days. Thus, a single treatment which affects the production of both spermatozoa and seminal plasma might yield results which, when measured as semen parameters, differ in time to response, in type and direction of response, and in duration of response to treatment. A course of exogenous androgen, for example, would cause a relatively rapid rise in seminal plasma volume but would have no immediate effect on sperm number and, therefore, would result in a fall in sperm concentration per millilitre due to a true dilution effect. This might well be misinterpreted as an androgen effect on sperm output if only sperm concentration per millilitre is considered. Then, over a period of several weeks, the depressive effect of the androgen on sperm production, via the mechanism of gonadotrophin inhibition, would result in a marked drop in total spermatozoa per ejaculate but the seminal plasma volume would remain high. When the 
treatment was stopped, there would be a rapid decrease in seminal plasma volume, particularly since endogenous androgen production would be suppressed and would take some time to recover, with no immediate effect on sperm number and, therefore, a rise in sperm concentration per millilitre due to a concentration effect. The return to normal pre-treatment seminal plasma volume would precede the return to normal total spermatozoa per specimen by several weeks, thus yielding a subsequent decrease in sperm concentration per millilitre, followed by a return to normal. Thus, the effect of androgen on sperm production cannot be expressed solely in terms of changes in sperm concentration per millilitre, since this is confounded by changes in both spermatogenesis and seminal plasma production.

It follows from these data and deductions that sperm concentration per millilitre, by itself, is not adequate for the expression of treatment results or of fertility levels. Furthermore, one must account for the complex interrelationships between total spermatozoa per specimen and seminal plasma volume, in a particular study or under specified conditions of treatment, before this term can be used with any assurance in a statistical analysis. The setting of a minimum value of sperm concentration per millilitre-20,000,000/ml (MacLeod \& Gold, 1951) -and the decision that this is the point of demarcation for fertility and infertility is a case in point. The inadequacy of sperm concentration per millilitre by itself, for this purpose, is evident when one considers the sperm-plasma relationships reported above and also the almost infinite number of pairs of values for sperm concentration per specimen and specimen volume which could be combined to yield the same sperm concentration per millilitre value. The physiological validity of such a minimum value of sperm concentration per millilitre for fertility in man is not supported by the lack of success with homologous artificial insemination where either the split-ejaculate technique was used to produce a sperm-rich fraction or where the spermatozoa were concentrated by centrifugation and removal of seminal plasma, i.e. where sperm concentration per millilitre was increased without change in sperm concentration per specimen. Finally it must be reiterated that, although the existence of a relationship between sperm concentration per millilitre and the likelihood of conception has been accepted by most of the workers in this field, the question of cause and effect remains open. The fact that the measurement of sperm concentration in a single specimen from each of hundreds or even thousands of donors may help to partition a large population into quality groups by likelihood of conception, does not necessarily mean that sperm concentration per se is directly and causally related to the probability of conception.

It is hoped that the data and discussion presented in this and in a preceding paper (Freund, 1962) will serve as a stimulus for an increase in the research activity directed to an understanding of human sperm production. It is suggested that such activity must be based on measurements of Dso after depletion of the extra-gonadal sperm reserve. It is only after such reliable and repeatable measurements are made that studies can be designed to measure specific treatment effects. 


\section{ACKNOWLEDGMENTS}

This investigation was supported by PHS GM-06014-04 and, in part, by PHS GM-06880-03 from the Division of General Medical Sciences, National Institutes of Health, United States Public Health Service. The author gratefully acknowledges the technical assistance of Mrs Gloria Edwards and Miss Sandra Frank. The author is a Career Scientist of the Health Research Council of the City of New York (I-218).

\section{REFERENCES}

Almquist, J. O. \& Amann, R. P. (196I) Reproductive capacity of dairy bulls. II. Gonadal and extragonadal sperm reserves as determined by direct counts and depletion trials: dimensions and weight of genitalia. 7. Dairy Sci. 44, 1668.

Almquist, J. O. \& Hale, E. B. (1956) An approach to the measurement of sexual behaviour and semen production of dairy bulls. Proc. IIIrd int. Congr. Anim. Reprod., Cambridge, p. 50.

Almquist, J. O., Amann, R. P. and Hale, E. B. (1961) Measurement of sperm production and its relation to sperm output and reserves in dairy bulls. Proc. IVth int. Congr. Anim. Reprod., The Hague, p. 270.

Almquist, J. O., Amann, R. P. \& O'Dell, W. T. (1958) Sperm reserves of dairy bulls as determined by depletion trials and postslaughter sperm counts. 7 . Dairy Sci. 41, 733.

Amann, R. P. (1961) Reproductive physiology of the male bovine. Ph.D. thesis, The Pennsylvania State University, University Park.

Amann, R. P. \& Almouist, J. O. (1961) Reproductive capacity of dairy bulls. V. Detection of testicular deficiences and requirements for experimentally evaluating testis function from semen characteristics. F. Dairy Sci. 44, 2283.

Amann, R. P. \& AlmQuist, J. O. (1962) Reproductive capacity of dairy bulls. VIII. Direct and indirect measurement of testicular sperm production. 7. Dairy Sci. 45, 774.

Boyd, L. J. \& VANDEMARK, N. L. (1957) Spermatogenic capacity of the male bovine. I. A measurement technique. 7. Dairy Sci. 40, 689.

Branton, C., D'Arensbourg, G. \& Johnston, J. E. (1952) Semen production, fructose content of semen, and fertility of dairy bulls as related to sexual excitement. F. Dairy Sci. 34, 801 .

Collines, W. J., Bratton, R. W. \& Henderson, C. R. (1951). The relationship of semen production to sexual excitement of dairy bulls. F. Dairy Sci. 34, 224.

Doggetr, V. C. (1956) Periodicity in the fecundity of male rabbits. Amer. J. Physiol. 187, 445.

Doggetr, V. C. \& Keilers, R. K. (1962) Periodicity in the fecundity of human males. Anat. Rec. 142, 227.

Dukelow, W. R., Frederick, E. C. \& Graham, E. F. (1960). Frequency of ejaculation in the bovine. 7. Dairy Sci. 43, 1335.

Frederick, E. C. (1957) Sexual performance in dairy bulls as related to frequency of ejaculation. Ph.D. thesis, University of Minnesota, St. Paul.

FREUND, M. (1962) Interrelationships among the characteristics of human semen and factors affecting semen specimen quality. 7. Reprod. Fertil. 4, 143.

Hafs, H. D. \& KNisely, R. G. (1960) Some norms of sperm output for dairy and beef bulls. Quart. Bull. Mich. agric. Expt. Sta. 43, 270.

Hafs, H. D., Hoyt, R. S. \& BRATton, R. W. (1959) Libido, sperm characteristics, sperm output, and fertility of mature dairy bulls ejaculated daily or weekly for thırty-two weeks. 7. Dairy Sci. 42, 626.

Hafs, H. D., Knisely, R. C. \& Desjardins, C. (1962). Sperm output of dairy bulls with varying degrees of sexual preparation. F. Dairy Sci. 45, 788.

Hale, E. B. \& Almouist, J. O. (1960). Relation of sexual behavior to germ cell output in farm animals. 7. Dairy Sci. 43 (Suppl.), 145.

Hale, E. B., Almquist, J. O. \& Thacker, D. L. (1953) Observations on the sexual behavior and semen production of dairy bulls. J. Dairy Sci. 35, 576 .

Harvey, G. \& Jackson, M. H. (1945) Assessment of male fertility by semen analysis. Lancet, ii, 99 and 134.

Hotchkiss, R. S., Brunner, E. K. \& Grenley, P. (1938). Semen analysis of two hundred fertile men. Amer. 7. med. Sci. 196, 362.

Hupp, E. W., Austin, J. W., Parish, N. R. \& Murphree, R. L. (1962) Sperm production of hereford bulls at different intensities of collection. F. Anim. Sci. 21, 272. 
LAmpe, E. H. \& Masters, W. A. (1956) Problem of male fertility. II. Effect of frequent ejaculation. Fertil. Steril. 7, 123.

MACLEOD, J. \& GoLD, R. Z. (1951) The male factor in fertility and infertility. II. Spermatozoon counts in 1000 men of known fertility and in 1000 cases of infertile marriage. $\mathcal{F}$. Urology, 66, 436.

MacLeod, J. \& Hzim, L. M. (1945) Characteristics and variations in semen specimens in 100 normal young men. $\mathcal{F}$. Urology, 54, 474.

MacLeod, J. \& Hotchkiss, R. S. (1946) Semen analysis in 1500 cases of sterile marriage. Amer. F. Obst. Gynec. 52, 34.

Murphy, D. P. (1962) The effect of ejaculation upon the sperm count: Report of a case. F. Urology, 88, 431 .

Ortavant, R. (1952) Recherches sur la spermatogenese des animaux domestiques. Etude des reserves spermatiques chez le belier. C.R. Soc. Biol., Paris, 146, 1086.

Ortavant, R. (1959) Spermatogenesis and morphology of the spermatozoon, Reproduction in Domestic Animals, vol. II, chap. I. Academic Press, New York.

VanDemark, N. L. (1956) Quantitative aspects of semen production in bulls. Proc. IIIrd int. Congr. Anim. Reprod., Cambridge, p. 80. 